\title{
Correlation of infertility with altered tubal morphology and function in mice with salpingitis induced by a human genital-tract isolate of Chlamydia trachomatis
}

\author{
M. Tuffrey*, F. Alexander*, C. Inman $†$ and M. E. Ward $\ddagger$ \\ *Division of Sexually Transmitted Diseases, MRC Clinical Research Centre, Watford Road, \\ Harrow, Middlesex HAI 3UJ, UK, and Departments of $\dagger$ Electron Microscopy and \\ $\ddagger$ Microbiology, Southampton University Medical School, Southampton General Hospital, \\ Southampton SO9 $4 X Y, U K$
}

\begin{abstract}
Summary. Progesterone-treated $\mathrm{C} 3 \mathrm{H}$ mice were inoculated into the uterus or ovarian bursa with a human genital tract isolate of $C$. trachomatis (serovar E), or with control medium alone. The mice were then observed at various times up to 260 days after inoculation. Before being killed the mice were given pituitary gonadotrophins to induce oyulation. Eggs were sought in the oviducts and ciliary activity in the fimbrial and ampullary sections of the oviducts was determined by light microscopy, before detailed examination by scanning electron microscopy.

Eggs were visible in all control oviducts and both mucosal ultrastructure and ciliary activity appeared normal. By contrast, eggs were not recovered from the inoculated oviducts of mice infected intrabursally, nor was ciliary activity observed up to 28 days after inoculation. After this, ciliary activity reappeared but eggs were still not transported to the oviduct. Ultrastructural studies suggested that severe mucus congestion accompanied by tubal oedema and loss of ciliated epithelia play a major role in the aetiology of chlamydial-induced tubal damage. Infertility following chlamydial salpingitis could be associated with failure of egg transportation to the oviduct. Egg transport was still impaired even when luminal ciliary activity, ultrastructural integrity and patency had recovered.

Our results suggest that chlamydial salpingitis in this mouse model closely resembles the human disease in its pathology and consequences for fertility, making the model particularly relevant for research on chlamydial vaccine development.
\end{abstract}

Keywords: Chlamydia trachomatis; salpingitis; animal models

\section{Introduction}

Salpingitis caused by Chlamydia trachomatis in women often leads to infertility or a marked increased risk of ectopic pregnancy (Chow et al., 1987; Robertson \& Ward, 1988). In many regions of the world it is likely that $C$. trachomatis is the single major cause of tubal infertility. Animal models are essential to study the immunopathological basis of Chlamydia-induced tubal damage and its prevention. Non-human primate models are of particular relevance as they appear to resemble closely the human disease (Patton, 1985). Unfortunately, non-human primates are scarce, expensive and thus inappropriate for the large scale breeding experiments necessary to ascertain the consequences of chlamydial infection for subsequent fertility. The upper genital tract of mice can be infected with the $C$. trachomatis mouse pneumonitis agent and the mice may subsequently develop infertility (Swenson et al., 1983; Swenson \& Schachter, 1984), although this murine strain of $C$. 
trachomatis differs from human isolates both antigenically and in DNA re-association studies. Consistent chlamydial infection of the mouse oviduct can also be achieved using human genital tract isolates of $C$. trachomatis (Tuffrey et al., 1986a, b). This model, for the first time, permitted long-term, statistically adequate studies on defective egg transport and the mechanisms responsible for Chlamydia-induced tubal infertility. Egg transport was impaired even in the absence of tubal occlusion. One possibility is that the epithelial surface of the oviduct is damaged, impairing its functional integrity. There have been several studies on the ultrastructure of the oviduct following chlamydial infection (reviewed by Patton, 1985), but there has been no attempt to correlate sequential ultrastructural changes at the luminal surface of the oviduct with functional markers of tubal integrity such as ciliary activity, ovum transport and fertility. This paper reports the consequences of chlamydial infection for mouse oviduct function and ultrastructure, in relation to our previous studies on Chlamydia-induced infertility in the mouse.

\section{Materials and Methods}

Mice. Syngeneic C3H mice, 6-8 weeks old, bred in the specific pathogen-free (SPF) unit at the National Institute for Medical Research (Mill Hill, London, UK) were used.

C. trachomatis strains. $C$. trachomatis NI.1 was isolated from the endocervix of a contact of a man with nongonococcal urethritis and was serotyped as serovar $\mathrm{E}$, one of the commonest genital tract serovars. The isolate was passed serially in McCoy cells. Chlamydiae from the tenth passage, suspended in 2SP sucrose-phosphate buffer (68.46 g sucrose; $2.088 \mathrm{~g} \mathrm{~K}_{2} \mathrm{HPO}_{4} ; 1.088 \mathrm{~g} \mathrm{KH}_{2} \mathrm{PO}_{4}$; water I litre; $\mathrm{pH} 7 \cdot 2$ ) containing $10 \%$ fetal calf serum, were used for subsequent inoculation. This inoculum was free of contaminating mycoplasma or bacteria and was known to cause salpingitis in mice.

Infection of mice. Progesterone treatment enhances murine infection of mice with C. trachomatis (Tuffrey \& Taylor-Robinson, 1981; Tuffrey et al., 1986a). All the mice were therefore given a single dose of $2.5 \mathrm{mg}$ progestagen (Depo-Provera, Upjohn, Kalamazoo, MI, USA) subcutaneously 7 days before inoculation with strain NI.I (test) or 2SP suspending medium (control). The animals were anaesthetized with $0.1 \mathrm{ml} / 30 \mathrm{~g}$ body weight of a mixture made up with 1 part Hypnorm (IM) (Janssen Pharmaceutical Ltd, Grove, Oxford, UK) in 2 parts water and I part Hypnovel(ii) (Roche Products, Welwyn Garden City, Herts, UK). The inoculum was introduced either directly into the right uterine horn (intrauterine) or under the right ovarian bursa (intrabursal) and thus into an oviduct. Mice were given $5 \times 10^{5}$ inclusion-forming units (ifu) of strain NI.1 by the intrauterine route or $5 \times 10^{4}$ ifu by the intrabursal route. The surgical procedures have been described previously (Tuffrey et al., 1986a).

Detection of chlamydiae. Cervical/vaginal swabs were taken on Days 7 and 13 after inoculation to confirm infection of the genital tract. Each swab was expressed in $1 \mathrm{ml}$ of cold 2SP medium which was stored in liquid nitrogen until subsequent inoculation by centrifugation onto cycloheximide-treated McCoy cells for conventional chlamydial isolation (Thomas et al., 1977).

Detection of eggs. Administration of pituitary gonadotrophins to female mice induces ovulation, irrespective of their oestrous phase. Infected mice and their controls were induced to ovulate from Day 8 to Day 260 after inoculation by giving them i.p. injections of 5 i.u. PMSG (Folligon: Intervet, Cambridge, UK) intraperitoneally, followed by 5 i.u. hCG (Chorulon: Intervet) about $45 \mathrm{~h}$ later. Eggs were sought in the oviducts on the following day. The mice were killed and ovaries and oviducts were dissected out and placed in a watch glass in 0.2-0.3 $\mathrm{ml} 0.5 \mathrm{M}$-Hepes-buffered MEM medium. Clumps of eggs surrounded by cumulus cells could be seen in control oviducts at this time by using a stereomicroscope.

Assessment of ciliary activity. After the oviducts had been examined for the presence or absence of eggs, the ciliated fimbrial and ampullary sections of the tubes were dissected out under a stereomicroscope. The ampullary region was then sliced along its length with a microsurgical knife to expose the luminal epithelial surface. The specimen was examined with an inverted microscope to determine the presence and vigour of actively beating cilia within both regions, then transferred to fixative for scanning electron microscopy (SEM).

SEM studies. Mouse oviducts were fixed in $5 \%(\mathrm{v} / \mathrm{v})$ glutaraldehyde in $0.1 \mathrm{M}$-cacodylate $(\mathrm{pH} 7 \cdot 4)$ and stored at $4{ }^{\circ} \mathrm{C}$ in fixative until processing. After a wash in buffer $(0.1 \mathrm{M}$-cacodylate and $0.5 \mathrm{M}$-sucrose $\mathrm{pH} 7.4)$ the ducts were postfixed for $1 \mathrm{~h}$ in $2 \%(\mathrm{w} / \mathrm{v})$ osmium tetroxide, rinsed in distilled water, dehydrated through graded ethanols, then critical-point dried in liquid carbon dioxide using a Polaron E3000 drier. In some cases oviducts were first straightened out and attached to pieces of card before fixation, then were cut transversely with a small scalpel into 6 or 7 segments before processing. The dried segments were mounted with the luminal surfaces uppermost and coated with approximately $20 \mathrm{~nm}$ gold/palladium to facilitate examination in an Hitachi S800 field emission SEM (resolution $2 \mathrm{~nm})$ at $15 \mathrm{kV}$ accelerating voltage. 


$\begin{aligned} & \text { Day after } \\ & \text { inoculation } \\ & \text { Intrabursal inoculation }\end{aligned}$
Intrauterine inoculation

Fig. 1. Summary diagram showing the effects of intrabursal or intrauterine inoculation of Chlamydia trachomatis on ovum transport and ciliary activity in mouse oviducts. Normal or impaired function is indicated by the shaded or unshaded symbols respectively.

\section{Results}

The ultrastructure study used 30 mice: 15 were inoculated intrabursally (10 with NI.1 and 5 with 2SP) and the remaining 15 were inoculated via the intrauterine route. One mouse from each group plus a control mouse was killed at various times from Days 8 to 260 after inoculation. Data on oviduct function and ciliary activity were available for 24 of these mice as shown in Fig. 1 .

\section{Confirmation of infection}

Chlamydiae were recovered from vaginal swabs taken from all mice inoculated into the uterus with NI. 1 on both Days 7 and 13 after inoculation, and from all except 2 mice inoculated intrabursally on Day 13 after challenge. However, there was evidence at necropsy for both of these last 2 mice of hydrosalpinx formation.

\section{Egg transport}

Eggs were found in both oviducts of all the control mice which were inoculated with Medium 2SP alone (Fig. 1). By contrast, no eggs were transported to the oviducts on the injected side in any of the mice inoculated with chlamydiae via the intrabursal route, nor were they found in oviducts on the non-injected side (data not shown) in these mice killed on Days 28, 35 and 42 after inoculation. The failure of egg transport occurred later in mice inoculated by the intrauterine route. Egg transport was impaired after Day 15 on the injected side or from Day 35 on the non-injected side and no eggs were recovered from oviducts on either side in mice killed 42 days after inoculation. 

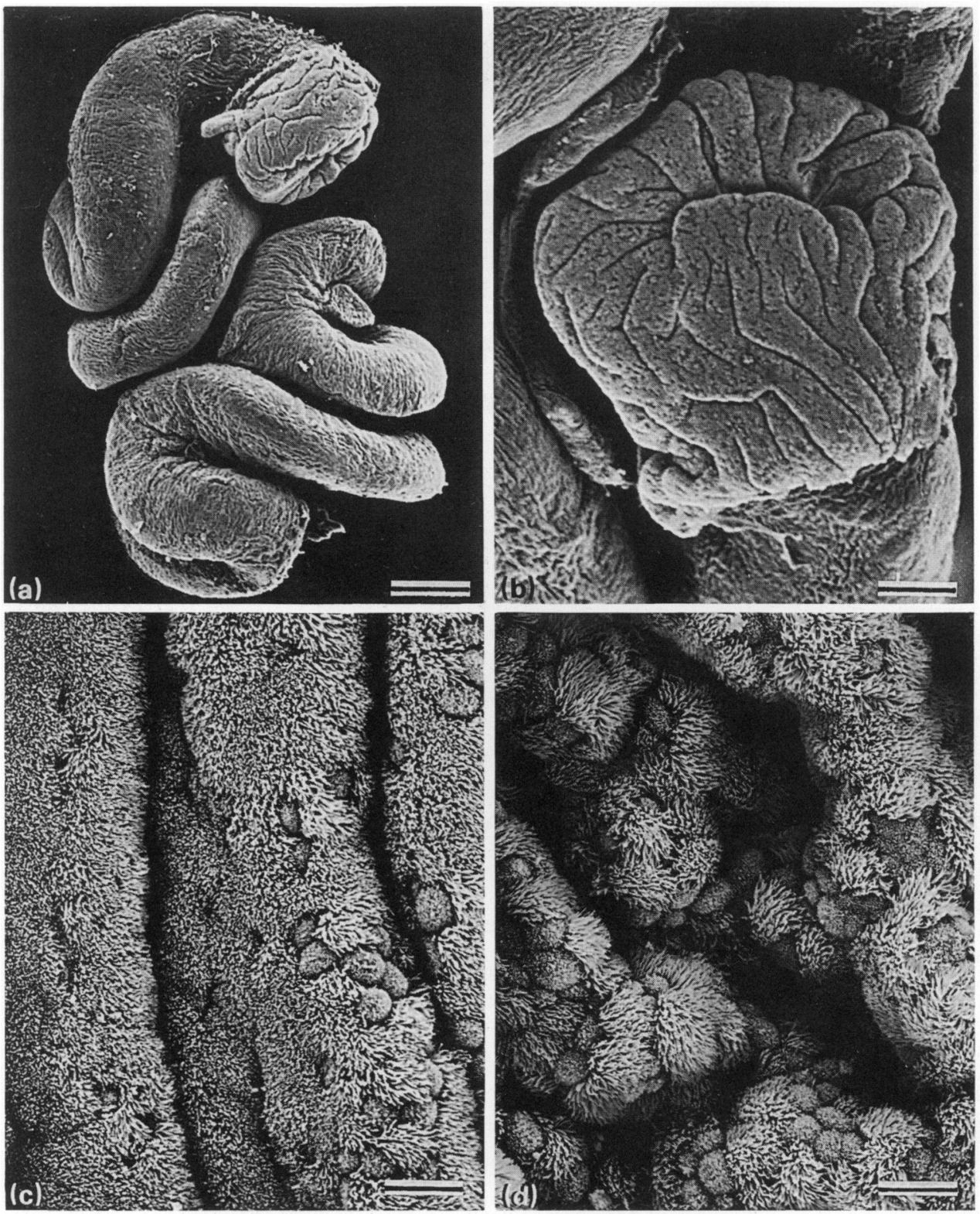

Fig. 2. Scanning electron micrograph (SEM) of normal oviducts from control mice showing (a) whole oviduct. (b) the infundibulum. (c) ciliated epithelia from the infundibular region. (d) ciliated and non-ciliated epithelia of the ampullary region. The bars represent (a) 218 . (b) 84 . (c) 12 and (d) $9 \mu \mathrm{m}$

\section{Ciliary activity}

Loss of ciliary movement in the fimbrial and ampullary regions of the oviduct was associated with failure of egg transportation up to Day 28 after inoculation. In oviducts studied on Days 35. 42 and 56 after inoculation, some fimbrial ciliary activity had returned, although the eggs were not transported and there was still no apparent ciliary activity within the ampullary region. From 


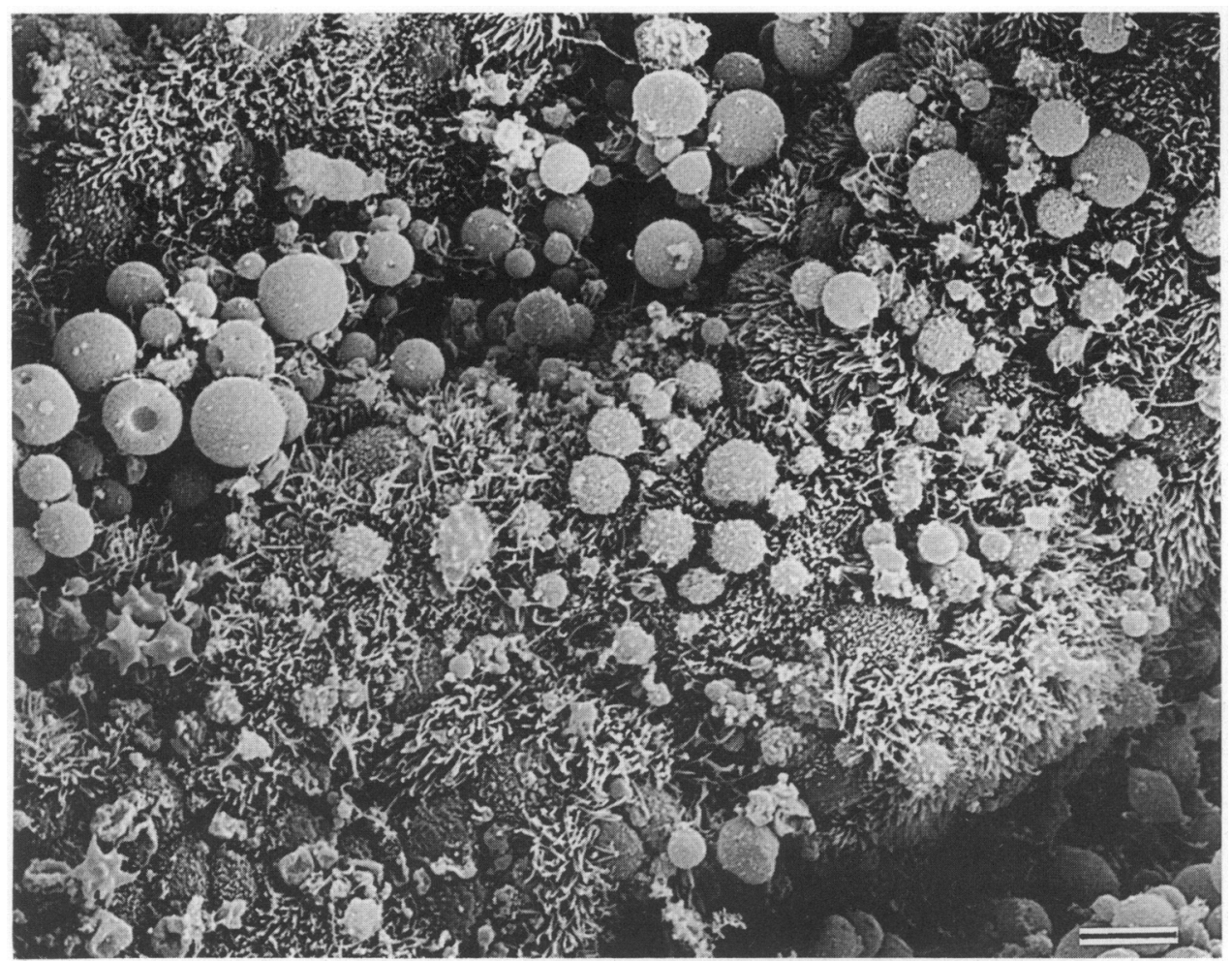

Fig. 3. SEM of the mucosal surface of the mouse oviduct 8 days after intrabursal inoculation with $C$. trachomatis. The cilia are already disorganized and there are numerous globules of dried mucus. The bar represents $7 \cdot 5 \mu \mathrm{m}$.

Day 84 after inoculation, both fimbrial and ampullary ciliary activity appeared normal but egg transport was still impaired.

\section{SEM studies}

The typical appearance and size of normal mouse oviduct is shown in Fig. 2. The normal lining of the infundibular region was fimbriated (Fig. 2b, c) with a high density of ciliated epithelia (Fig. 2c). In the ampullary region (Fig. $2 \mathrm{~d}$ ) the ciliated epithelial cells were less dense and interspersed with columnar epithelial cells which were covered with microvilli.

At 8 days after intrabursal inoculation, the infected tube failed to transport ova and its walls appeared thickened and oedematous. The surface of this tube was characterized by marked mucus hypersecretion (Fig. 3) with matted and apparently disorganized cilia but few inflammatory cells. Mucus hypersecretion in intrabursally inoculated oviducts reached a peak at Day 15, with the ampullary region of the tube blocked with exudate (Fig. 4a). This exudate consisted mainly of mucus droplets (Figs 4b,c) with the occasional inflammatory cell (Fig. 4c). The underlying epithelium was disorganized, with a loss of ciliated epithelial cells and breakdown of ciliary structure (Fig. 4d). Mucus hypersecretion continued to be observed as long as 84 days after infection. Secondary bacterial infection, probably gram-negative rods, was occasionally observed in tubes with mucus hypersecretion (Fig. 5a,b). Marked disorganization of the ciliated epithelial surface was still apparent at Day 35.

Hydrosalpinx formation was first observed as early as 28 days after intrabursal infection. Figure 6(a) shows a transversely sectioned normal (control) tube. Fimbriae are apparent within the 

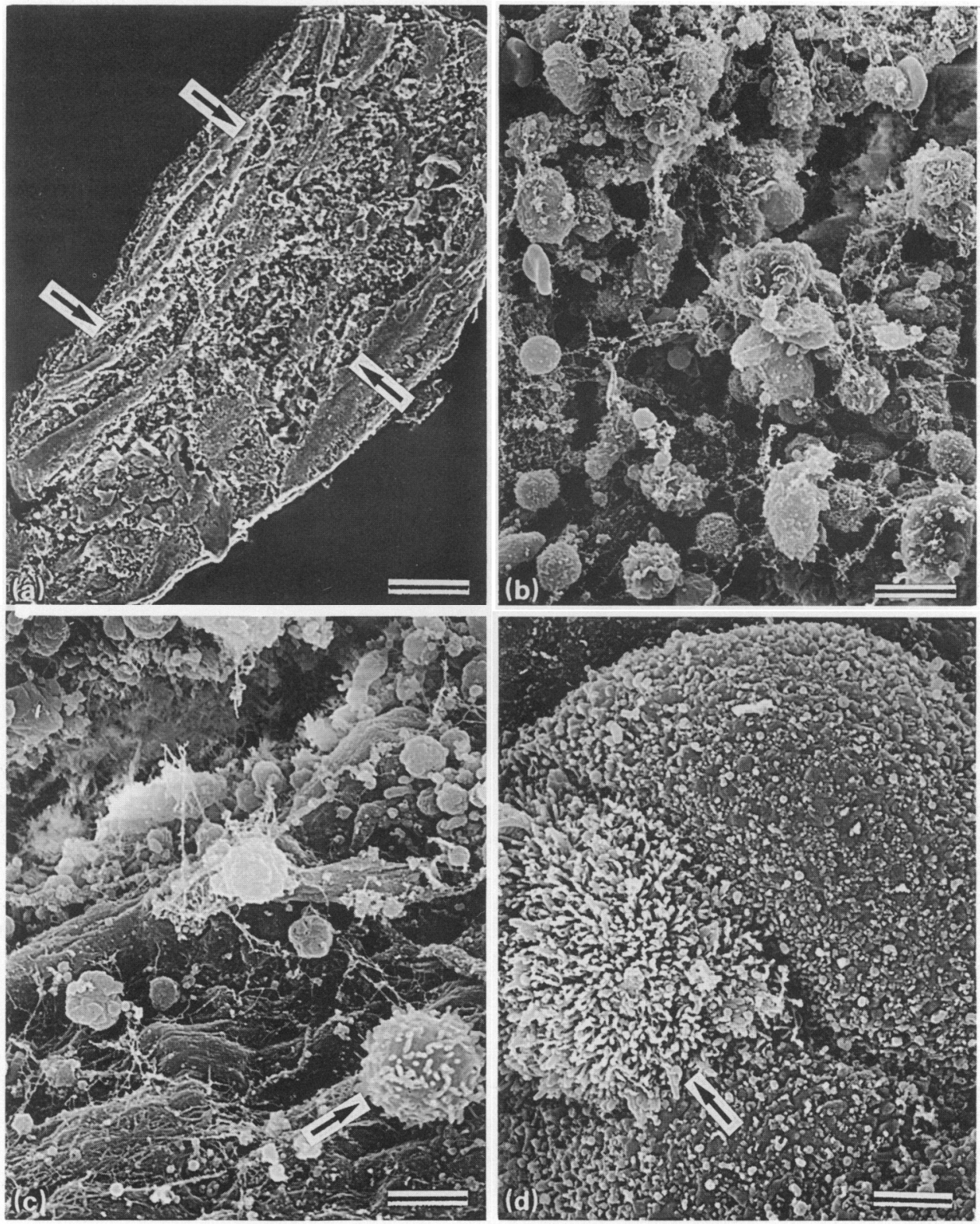

Fig. 4. SEM of mouse oviduct 15 days after intrabursal inoculation. (a) Longitudinal section along the oviduct showing the oviduct lumen (arrows) already blocked with exudate. (b) Higher power of (a): the exudate consists mainly of dried mucous secretion plus cell debris. (c) Occasional inflammatory cells (arrowed) were interspersed amongst this debris. (d) A small area of the epithelium showing the major extent of epithelial disruption and destruction of the cilia (arrowed) beneath the exudate. The bars represent (a) 104, (b) 8 , (c) 3 and (d) $2.5 \mu \mathrm{m}$.

unobstructed lumen of this tube. By contrast Fig. 6(b) shows the exudate-obstructed lumen of a similar region of a Chlamydia-infected tube. The marked hydrosalpinx and epithelial compression frequently associated with such a blockage is shown in Fig. 6(c). Within this compressed region the mucosal lining of the tube nevertheless showed evidence of patchy regeneration of the ciliated 

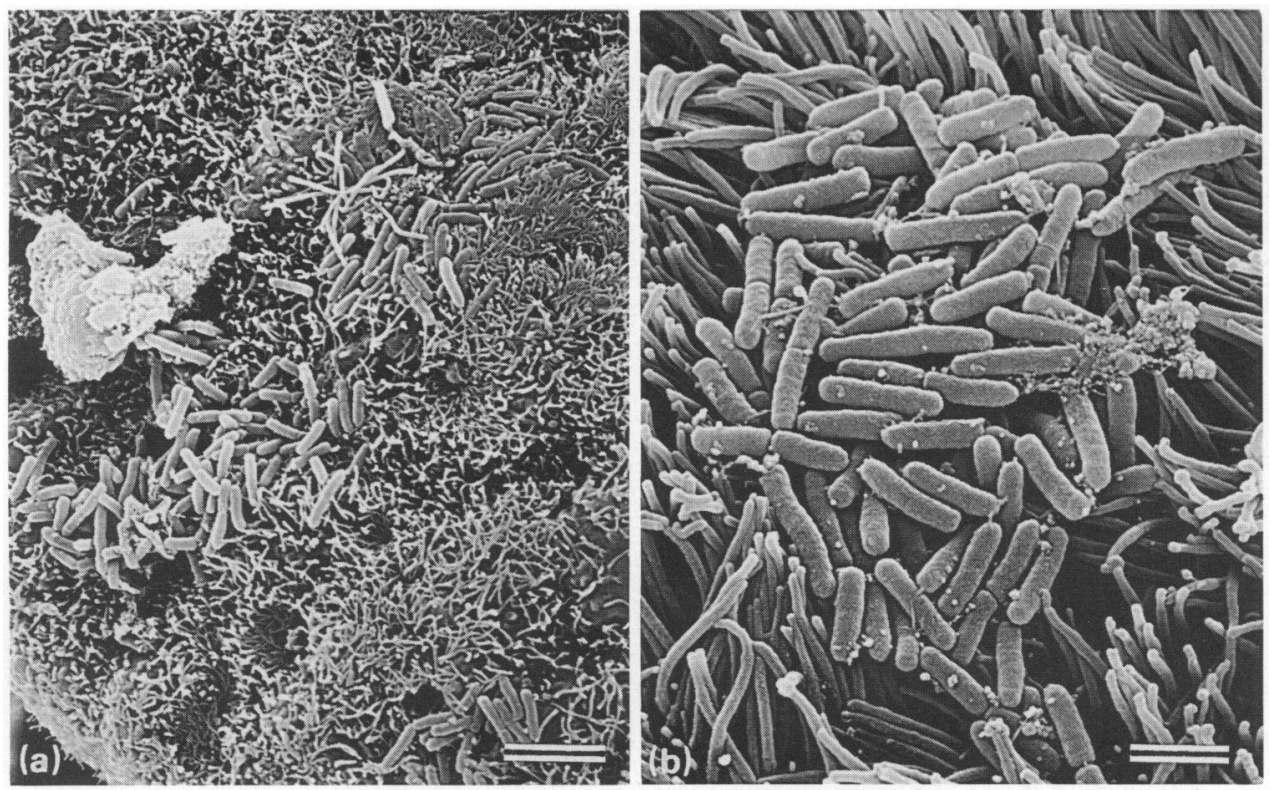

Fig. 5. SEM of mouse oviduct 56 days after intrauterine inoculation. (a) Low-power picture showing the extent of secondary infection with bacterial rods. (b) Higher magnification view of similar area. The bars represent (a) 4 and (b) $1.5 \mu \mathrm{m}$.

epithelium (Fig. 6d). Occasional inflammatory cells were observed on the epithelium (Fig. 7a), readily distinguishable by their size and topography from mucus droplets but the regenerated cilia were still matted together, presumably with mucus (Fig. 7b). Blockage of the ampullary region of the tubes and associated hydrosalpinx was noted as late as 71 days after infection.

By 161 and 260 days after intrabursal challenge, ovum transport was still impaired but paradoxically the oviduct lumen looked relatively normal, with just patchy areas of epithelial disruption and moderate amounts of mucus secretion (data not shown).

\section{Discussion}

The major advantage of the mouse model is that it is cheap, animals are readily available, and it is possible to correlate pathological changes in the oviduct with their consequences for fertility. Alternative, non-primate, experimental models of chlamydial salpingitis exist, but in our view are less satisfactory. For example, in the rabbit model (Patton et al., 1982) there is doubt as to whether long-lasting infection is ever established. Both the guinea-pig model (White et al., 1979) and the cat model (Kane et al., 1985) use $C$. psittaci rather than the natural human pathogen $C$. trachomatis as the infecting organism. An alternative mouse model (Swenson et al., 1983) uses a non-human isolate of $C$. trachomatis, the mouse pneumonitis agent.

The use of progesterone to enhance chlamydial infection of the genital epithelia in the present model might be criticized. The function of the progesterone, a natural steroid, is believed to be the stabilization of the genital epithelia which otherwise vary with the oestrous cycle, increasing the number of target cells available for chlamydial infection (Tuffrey \& Taylor-Robinson, 1981). Infection can be achieved in the absence of the steroid (Tuffrey et al., 1986a), but it is clear that progesterone in no way diminishes the inflammatory response to chlamydial infection in the mouse.

The results of the present study showed that impairment of ovum transport occurred as early as 8 days after intrabursal inoculation of $C$. trachomatis and had spread to the uninoculated 

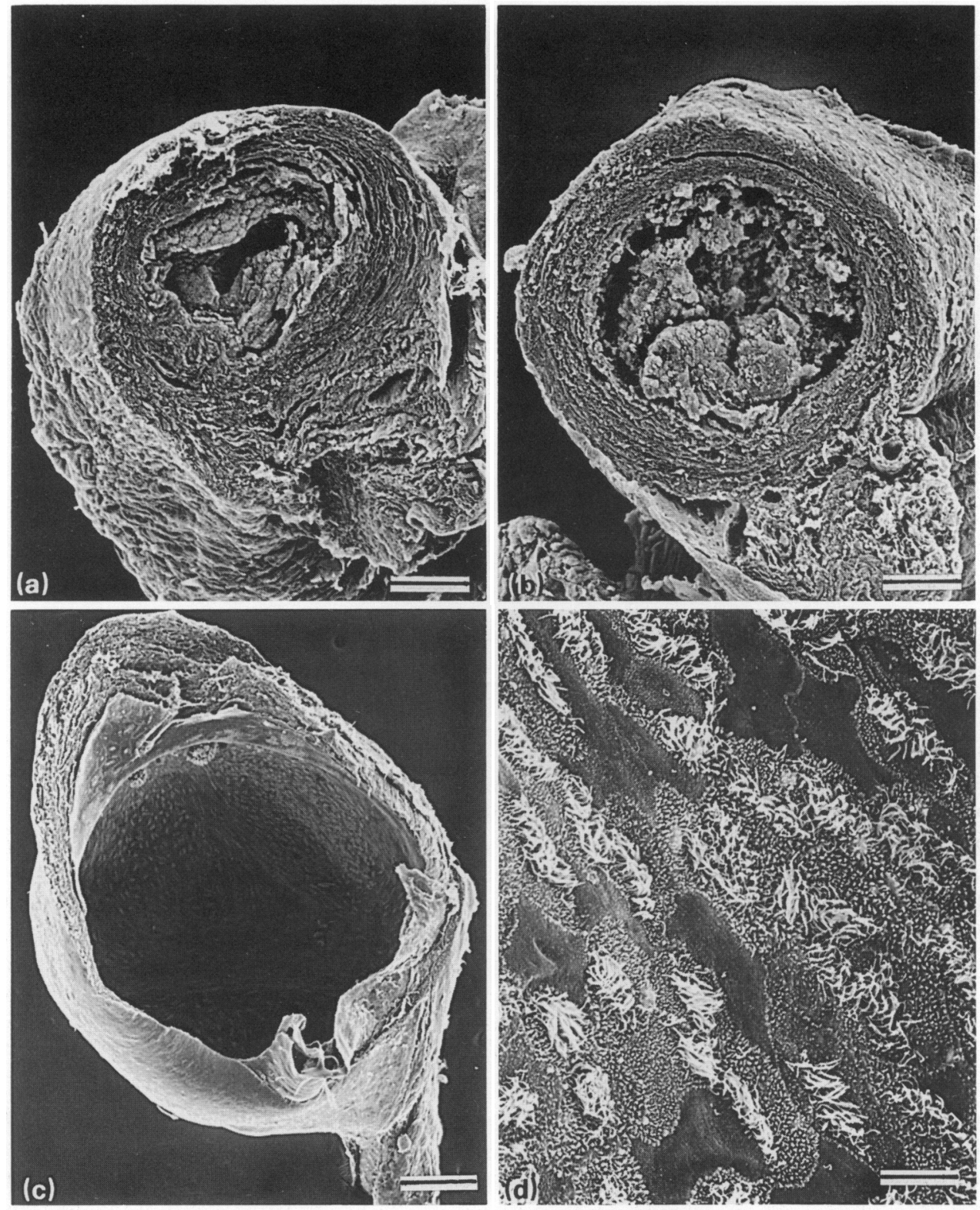

Fig. 6. SEM of transverse section of normal and Chlamldia-infected mouse oviduct. (a) Ampullary region of normal oviduct from a control mouse showing an unobstructed lumen with associated intraluminal fimbriae. (b) Similar region of infected oviduct 57 days after inoculation. The lumen is occluded with mucus and cell debris. (c) Infected oviduct with greatly enlarged lumen due to tubal obstruction and hydrosalpinx. (d) Detail within the lumen of (c) showing patchy regeneration of the compressed epithelial lining. The bars represent (a) 52. (b) 42. (c) 111 and (d) $11 \mu \mathrm{m}$.

contralateral tube by 28 days after infection. We assume this is the result of canalicular spread of chlamydiae via the uterus, as previously reported (Swenson et al., 1983; Tuffrey et al., 1986a). Intrauterine inoculation of $C$. trachomatis delayed the onset of impaired ovum transport to 21 

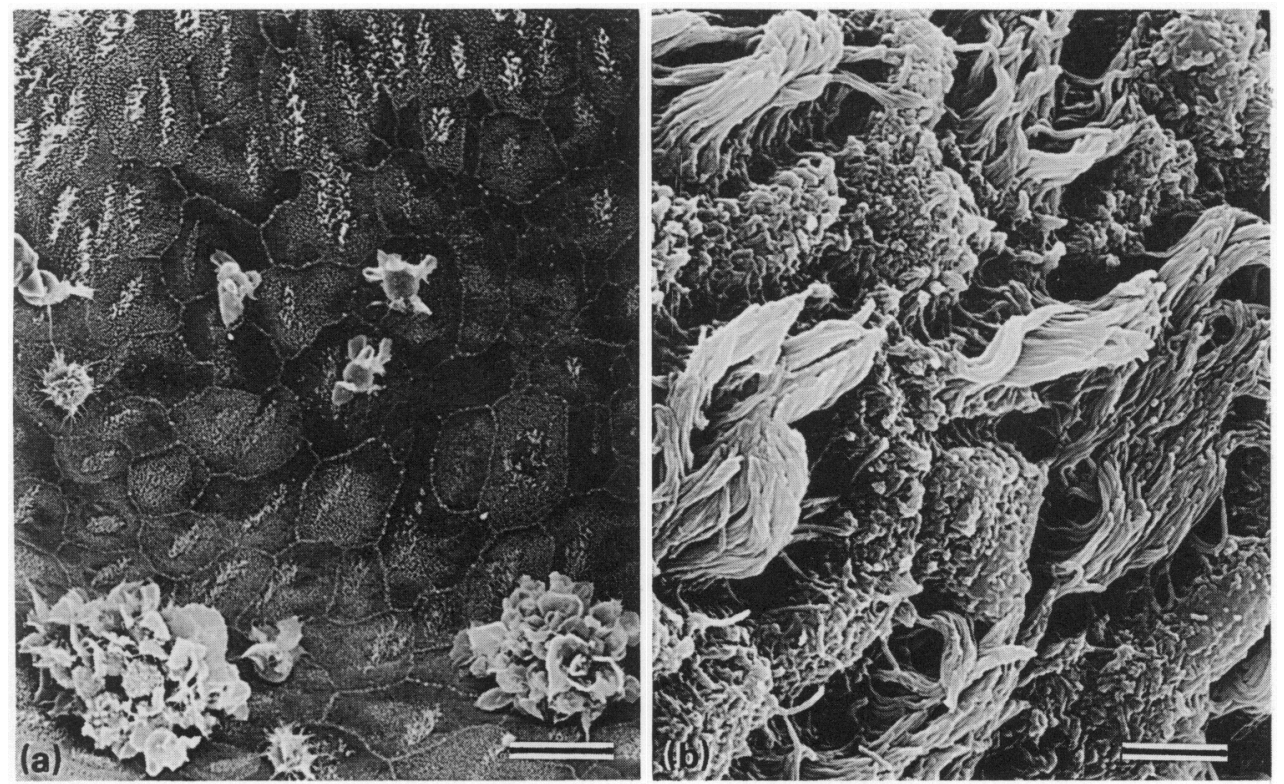

Fig. 7. SEM of inoculated mouse oviduct 57 days after challenge. (a) Inflammatory cells on the epithelial surface of a tube with a hydrosalpinx. (b) Cilia matted together with mucous secretion. The bars represent (a) 23 and (b) $3 \mu \mathrm{m}$.

days. However, once egg transport was impaired the effect was long-lasting, with mice 260 days after challenge still affected irrespective of the inoculation route. This impairment of egg transport following superovulation correlated well with infertility as previously reported (Tuffrey et al., 1986b). Pathological changes observed in this study by SEM also correlated well with those previously observed by light microscopy (Tuffrey et al., 1986a).

The most striking pathological change, first observed 8 days after intrabursal inoculation of $C$. trachomatis, was mucus congestion accompanied by tubal oedema and the loss of ciliated epithelial cells from the oviduct lumen. Few inflammatory cells were observed on the oviduct mucosa, although such cells have been observed in paraffin-wax sections (Tuffrey et al., 1986a). It is likely that by Day 8 any initial acute inflammatory response in the lumen has already subsided. A similar loss of ciliated epithelial cells and an absence of inflammatory cells was observed in pig-tailed macaques (Patton et al., 1987), together with evidence of T-cell infiltration in the stroma. It is unclear whether mucus congestion is primarily the result of impaired ciliary clearance induced by the loss of ciliated epithelial cells or is due to hypersecretion in response to the infection or associated lymphokines. The question is important as this study suggests that mucus accumulation is a major factor leading to tubal blockage. Moreover mucus in abnormal amounts may have been the "amorphous" substance observed at the luminal surface of blocked human Fallopian tubes (Tam et al., 1988). Perhaps mucus interferes with ovum transport in a manner similar to polycations, preventing the formation of transient adhesive bonds between the tip of the cilium and elements of the cumulus mass (Norwood et al., 1978). One possibility which could be tested in the mouse model is whether mucolytic or anti-inflammatory therapy early in salpingitis might reduce subsequent tubal damage.

Blockage of the narrow, infundibular region of the oviduct with mucus, interspersed inflammatory cells and necrotic epithelia was maximal 15 days after intrabursal challenge and was similar to that previously observed in paraffin-wax sections (Tuffrey et al., 1986a). In a number of mucuscongested and Chlamydia-infected tubes we observed secondary infection with bacterial rods. We speculate that, once mucus congestion with impaired ciliary clearance becomes established, the 
affected oviduct becomes vulnerable to secondary bacterial infection arising from the cervix. Mucus congestion, loss of ciliated epithelia, secondary bacterial infection or hydrosalpinx were only observed in Chlamydia-infected animals and never in control animals inoculated with the suspending medium alone. After intrabursal inoculation in those tubes not affected by hydrosalpinx, mucus congestion began to decrease gradually and ciliary activity to increase around Day 35. Occasional inflammatory cells were also present on the luminal surface at this time. It is possible that phagocytic cells, e.g. macrophages, play a role in eliminating the mucus.

Hydrosalpinx is a common outcome of chlamydial infection in both mice and women once the tube is blocked and drainage prevented. In the mouse model, hydrosalpinx formation was first observed 28 days after challenge, occurred in 10 animals, and was initially associated with marked compression and destruction of the underlying epithelium as has been reported for occluded human Fallopian tubes (Fedele et al., 1984; Tam et al., 1988). Recovery of the epithelium and ciliary activity in the mouse occurred later in tubes with a hydrosalpinx. Recovery of ciliary activity with time would explain the apparent disagreement in SEM studies of blocked human Fallopian tubes as to whether there is extensive loss of ciliated epithelium (Patek \& Nilsson, 1977; Fedele et al., 1984; Tam et al., 1988).

Oviducts collected 160-260 days after chlamydial infection had an apparently normal epithelial surface. Ciliary activity was vigorous and there were only patchy signs of epithelial disorganization. Nevertheless, ovum transport remained impaired in these late specimens. We can only speculate on the cause. One possibility is that the tubal lumen may still have been blocked at its narrowest region most difficult to examine by SEM. However, in women with tubal occlusion, surgical restoration of tubal patency often fails to achieve fertility and there is a high frequency of subsequent tubal ectopic pregnancy (Zamberletti et al., 1983; Tam et al., 1988). Chronically blocked human Fallopian tubes with hydrosalpinx show little correlation between the extent of de-ciliation and subsequent fertility (Fedele et al., 1984). Clearly factors other than tubal occlusion or deciliation must also be involved. Perhaps the metachronal rhythm of the regenerated cilia is disorganized and so ovum transport is impaired. Further investigations using both transmission electron microscopy and time lapse cine-microphotography would be necessary to investigate these possibilities.

The mouse model of chlamydial salpingitis resembles the human disease in the infecting chlamydial strains, the canalicular spread of infection, its pathology and the consequences for fertility. Preliminary immunological studies with this model indicate the importance of both host and Chlamydia-related factors for immunity (Tuffrey et al., 1982, 1986a). It seems highly unlikely that the severe consequences of chlamydial infection for human fertility can be prevented by community health programmes alone in the absence of an effective vaccine. Given the major advances now being made in chlamydial immunochemistry, including the successful expression of recombinant chlamydial antigens (Pickett et al., 1988) and the identification of neutralizing epitopes on the major outer membrane protein of Chlamydia (Zhang et al., 1987; Conlan et al., 1988), together with a greatly increased understanding of mucosal immunity, we believe it is time to assess the value of potential vaccines for preventing Chlamydia-induced infertility. We anticipate that this mouse model will play a major and relevant role in such a programme.

We thank Dr David Taylor-Robinson, Division of Sexually Transmitted Diseases, MRC Clinical Research Centre, for encouraging this collaborative study. Part of this work was supported by a grant from the Human Reproduction Programme of the World Health Organization.

\section{References}

Chow, W.H., Daling, J., Cates, W. \& Greenberg, R.S. (1987) Epidemiology of ectopic pregnancy. Epidem. Revs. 9, $70-94$.
Conlan, J.W., Clarke, I.N. \& Ward, M.E. (1988) Epitope mapping with solid phase peptides: identification of type-, subspecies-, species- and genus-reactive 
antibody binding domains on the major outer membrane protein of Chlamydia trachomatis. Molec. Microbiol. 2, 673-679.

Fedele, L., Zamberletti, D., Marchini, M., Vercellini, P. \& Cavalli, G. (1984) Degree of endosalpingeal deciliation (by SEM) in hydrosalpinx is not prognostic for post-surgical fertility. Acta eur. fertil. 15, 199-204.

Kane, J.L., Woodland, R.M., Elder, M.G. \& Darougar, S. (1985) Chlamydial pelvic infection in cats: a model for the study of human pelvic inflammatory disease. Genitourin. Med. 61, 311-318.

Norwood, J.T., Hein, C.E., Halbert, S.A. \& Anderson, R.G.W. (1978) Polycationic macromolecules inhibit cilia-mediated ovum transport in the rabbit oviduct. Proc. natn. Acad. Sci. USA 75, 4413-4416.

Patek, E. \& Nilsson, L. (1977) Hydrosalpinx simplex as seen by the scanning electron microscope. Fert. Steril. 28, 962-971.

Patton, D.L. (1985) Immunopathology and histopathology of experimental chlamydial salpingitis. Rev. Infect. Dis. 7, 746-753.

Patton, D.L., Halbert, S.A. \& Wang, S-P. (1982) Experimental salpingitis in rabbits provoked by Chlamydia trachomatis. Fert. Steril. 37, 691-700.

Patton, D.L., Kuo, C-C., Wang, S-P. \& Halbert, S.A. (1987) Distal tubal obstruction induced by repeated Chlamydia trachomatis salpingeal infections in pigtailed macaques. $J$. infect. Dis. 155, 1292-1299.

Pickett, M.A., Ward, M.E. \& Clarke, I.N. (1988) High level expression and epitope localisation of the major outer membrane protein of Chlamydia trachomatis serovar L1. Molec. Microbiol. 2, 681-685.

Robertson, J.N. \& Ward, M.E. (1988) Gonococcal and chlamydial infection in infertility and ectopic pregnancy. Contemp. Rev. Obstet. Gynae. 1, 60-66.

Swenson, C.E. \& Schachter, J. (1984) Infertility as a consequence of chlamydial infection of the upper genital tract in female mice. Sex. Transm. Dis. 11, 64-67.

Swenson, C., Donegan, E. \& Schachter, J. (1983) Chlamydia trachomatis-induced salpingitis in mice. $J$. infect Dis. 148, 1101-1107.
Tam, P.P.L., Mao, K.R. \& Mac-Moune Lai, F. (1988) The ultrastructural changes of the mucosa of blocked fallopian tubes. Br. J. Obstet. Gynaecol. 95, 802-807.

Thomas B.J., Evans, R.T., Hutchinson, G.K. \& TaylorRobinson, D. (1977) Early detection of chlamydial inclusions combining the use of cycloheximidetreated McCoy cells and immunofluorescence staining. J. clin. Microbiol. 6, 285-292.

Tufirey, M. \& Taylor-Robinson, D. (1981) Progesterone as a key factor in the development of a mouse model for genital-tract infection with Chlamydia trachomatis. FEMS Microbiol. Lett. 12, 111-115.

Tuffrey, M., Falder, P. \& Taylor-Robinson, D. (1982) Genital tract infection and disease in nude and immunologically competent mice after inoculation of a human strain of Chlamydia trachomatis. Br. J. exp. Path. 63, 539.546.

Tufirey, M., Falder, P., Gale, J. \& Taylor-Robinson, D. (1986a) Salpingitis in mice induced by human strains of Chlamydia trachomatis. Br. J. exp. Path. 67, 605-616.

Tuffrey, M., Falder, P., Gale, J., Quinn, R. \& TaylorRobinson, D. (1986b) Infertility in mice infected genitally with a human strain of Chlamydia trachomatis. J. Reprod. Fert. 78, 251-260.

White, H.J., Rank, R.G., Soloff, B.L. \& Barron, A.L. (1979) Experimental chlamydial salpingitis in immunosuppressed guinea pigs infected in the genital tract with the agent of guinea pig inclusion conjunctivitis. Infect. Immun. 26, 728-735.

Zamberletti, D., Fedele, L., Vercellini, P., Acaia, B. \& Candiani, G. (1983) The significance of scanning electron microscopy findings from the endosalpinx in tubal pregnancies. Acta eur. fertil. 14, 57-65.

Zhang, Y.X., Stewart, S., Joseph, T., Taylor, H.R. \& Caldwell, H.D. (1987) Protective monoclonal antibodies recognize epitopes located on the major outer membrane protein of Chlamydia trachomatis. $J$. Immunol. 138, 575-581.

Received 16 May 1989 